International Journal of Biological Research, $2(1)(2014) 21-22$
International Journal of Biological Research
Journal home page: $\begin{gathered}\text { www.sciencepubco.com/index.php/IJBR } \\ \text { doi: } 10.14419 / \text { ijbr.v2il.2252 } \\ \text { Short Communication }\end{gathered}$

\title{
Electrocardiographic abnormalities in young healthy sheep and goats
}

\author{
B. Sudhakara Reddy ${ }^{* 1}$, R. Venkatasivakumar ${ }^{2}$, S. Sivajothi ${ }^{3}$, Y. V. Pridhvidhar Reddy ${ }^{4}$ \\ ${ }^{l}$ Assistant Professor (Veterinary Medicine), T.V.C.C, C.V.Sc., S.V.V.U., Proddatur, Andhra Pradesh, India \\ ${ }^{2}$ Assistant Professor, Dept. of Veterinary Medicine, C.V.Sc., S.V.V.U., Proddatur, Andhra Pradesh, India \\ ${ }^{3}$ Assistant Professor, Dept. of Veterinary Parasitology, C.V.Sc., S.V.V.U., Proddatur, Andhra Pradesh, India \\ ${ }^{4}$ Assistant Professor, Dept. of Veterinary Gynecology and Obstetrics, C.V.Sc., S.V.V.U., Proddatur, Andhra Pradesh, India \\ *Corresponding author E-mail: bhavanamvet@gmail.com
}

\begin{abstract}
Electrocardiographic studies were done in clinically apparently healthy young sheep (26) and goats (32) in Andhra Pradesh. The electrocardiograms were recorded in standard base apex lead system. Five types of cardiac arrhythmias have been detected in this study, namely sinus tachycardia (18.9\%), respiratory sinus arrhythmia (8.6\%), sinoatrial block (6.8\%), second-degree atrioventricular block (3.4\%) and ventricular premature complex $(1.7 \%)$. These abnormalities were recorded in both sheep and goat.
\end{abstract}

Keywords: ECG, Young Sheep, Young Goats, Cardiac Arrhythmia.

\section{Introduction}

Electrocardiographic evaluation is most useful for sheep and goats with cardiac arrhythmias and the base-apex lead is the most common in large animal electrocardiography (Cebra and Cebra, 2002). Interpretation of ECG allows for diagnosis of a wide range of heart conditions, varying from unimportant to life threatening signs. During an arrhythmia, the heart beat is faster, slower or irregular. Most arrhythmias in large animals are physiological, however some of them are serious and life threatening. Pathological cardiac arrhythmias in goats were reported (Barbosaa et al., 2008). Although physiological cardiac arrhythmias were established in clinically healthy sheep and lambs (Pourjafar et al., 2011), there are few reports on physiological arrhythmias in goats (Smith \& Sherman, 2009). Recently normal ECG parameters in adult goats were recorded in Andhra Pradesh (Sudhakara Reddy et al., 2014). Meager literature is available on physiological cardiac arrhythmias in normal healthy young sheep and goats in India. Hence, an attempt was made to record the physiological cardiac arrhythmias in local clinically apparently healthy young sheep and goats in Y.S.R.District of Andhra Pradesh.

\section{Materials and methods}

The present study was done from January 2013 to February 2014 on healthy young sheep (26) and goats (32) belong to local cross breeds of Andhra Pradesh at Teaching Veterinary Clinical Complex, Proddatur. The animals were examined prior to ECG recording and were proved to be clinically healthy. None of the goat and sheep used in this study had any clinical signs of systemic diseases, respiratory, enteric, heart diseases and anemia. All animals were grazing in open green pasture with free access to water. The ECGs were recorded on a bipolar base apex lead, using limb lead I
(Radostits et al., 2007). Same procedure was adopted previously to record the normal ECG parameters in adult sheep (Sudhakara Reddy et al., 2013). All ECGs were recorded on a three channel electrocardiographic machine (Marks electronics, Chennai) with the paper speed of $25 \mathrm{~mm} / \mathrm{sec}$ and calibration of $10 \mathrm{~mm}$ equal to 1 $\mathrm{mV}$. Heart rate was calculated according to the R-R interval in lead-1. In arrhythmias, physical counting by auscultation was done to confirm the heart rate. Cardiac arrhythmias were identified based on the abnormalities in ECG.

\section{Results and discussion}

The normal electrocardiograms of all healthy sheep and goats (Fig.1) were recorded. Among the 58 animals five different types of cardiac arrhythmias have been detected in this study. Which includes sinus tachycardia $(18.9 \%)$, respiratory sinus arrhythmia $(8.6 \%)$, sinoatrial block (6.8\%), second-degree atrioventricular block $(3.4 \%)$ and ventricular premature complex $(1.7 \%)$. Variation in the rate and rhythm can occur in normal animals due to strong or varying autonomic influence but can also be a reflection of primary myocardial disease. Other factors such as acid-base and electrolyte imbalances can influence rate and rhythm (Radostits et al., 2007).

Electrocardiographic studies are infrequently reported in domestic animals. The electrocardiographic parameters have greatest value in recognizing and diagnosing arrhythmias in animals (Miller, 1999). Compared with numerous data for normal physiological cardiac arrhythmias available in bovine, ovine and caprine species, rarely studied about the electrocardiography studies in young sheep and goats and little amount of information is available about the physiological cardiac arrhythmias in these ruminants. 


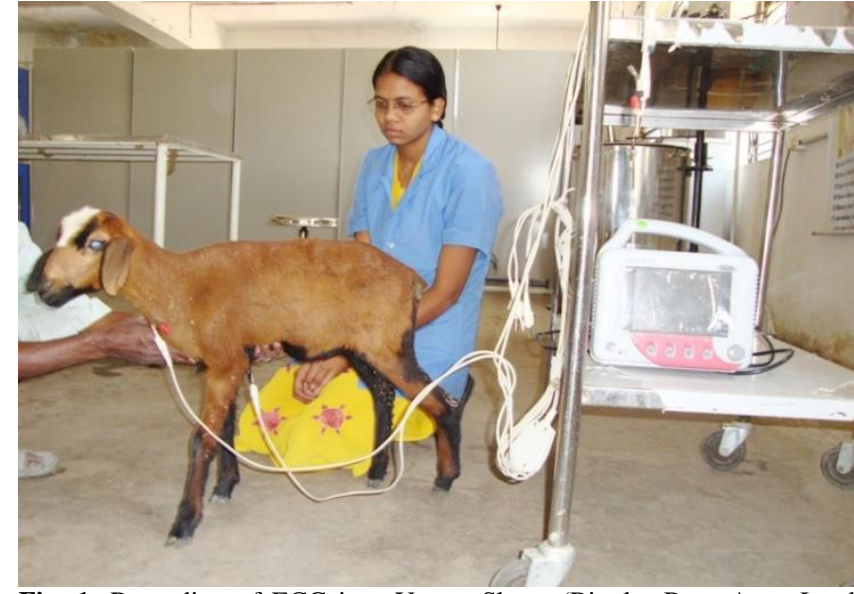

Fig. 1: Recording of ECG in a Young Sheep (Bipolar Base Apex Lead Method)

In the present study, sinus tachycardia (18.9\%) was noticed in four sheep and seven goats. The term sinus tachycardia has been used to describe an increase in heart rate caused by factors such as pain, excitement, exercise, hyperthermia, fall in arterial blood pressure (Radostits et al., 2007). The heart rate returns to normal when factors are removed or relieved. Because there were no clinical signs of cardiac problems in examined animals, this irregular cardiac rhythm could be categorized as physiological arrhythmia. Pourjafar et al. (2011) reported sinus tachycardia as the most common cardiac arrhythmia in newborn Iranian fat-tailed lambs. The physiological properties of foetal and neonatal myocardium make it intrinsically more vulnerable to high heart rates (Rudolph, 2001). Foetal tachycardia is an important cause of foetal morbidity and mortality (Wren, 2006).

Sinus arrhythmia $(8.6 \%)$ was noticed in two sheep and three goats is a normal physiological arrhythmia that occurs at slow resting heart beating rate and is connected with variation in the rate of discharge from the sinoatrial node which is related to variation in the intensity of vagal stimulations. It highly correlates with respiration so that discharge rate and heart rate increase and decrease during inspiration and expiration, respectively (Radostits et al. 2007). The high vagal tone is supposed to be the cause of arrhythmia in these animals (Rezakhani et al., 2004).

Sinoatrial block was detected $(6.8 \%)$ in one sheep and three goats. Rezakhani et al. (2010) suggested that the potential importance of the vagal tone for detection of certain arrhythmias was supported by greater occurrence of sinoatrial block during periods of relative bradycardia in ponies. Provided that it does not persist during and after exercise, it is considered as a physiological variant of normal rhythm (Radostits et al., 2007). In sinoatrial block, the sinus node fails to discharge or its impulse is not transmit ted over the atrial myocardium. It is associated with complete absence of heart sounds, of jugular atrial wave and of arterial pulse for one beat period. On the electro cardiogramme, there was a complete absence of P, QRS and T complex for one beat.

Second-degree atrioventricular block was noticed in one sheep and one goat $(3.4 \%)$. This is also called as artial heart block, this occurs when there is periodic interference with conduction at the atrioventricular node so that some atrial contractions are not followed by ventricular contraction. The electrocardiogram shows the presence of a $\mathrm{P}$ wave but complete absence of the subsequent QRS and $\mathrm{T}$ waves at the blocked beat. Second degree atrioventricular block is extremely common newborn due to variations in vagal tone. It can be abolished by exercise or the administration of atropine. Second degree atrioventricular block can be associated with myocarditis in the horse its presence has been associated with decreased racing performance by some clinicians (Radostits et al., 2007). There is usually no necessity to treat this arrhythmia specifically and treatment is generally directed at the underlying cause.

Ventricular premature complex was recorded $(1.7 \%)$ in one goat Ventricular premature complexes are characterized by bizarre
QRS morphology. Premature complexes of all sited origins are indicative of myocardial disease, one exception being the occurrence of atrial premature complexes accompanying cases of gastrointestinal disease in cattle (Radostits et al., 2007). Ventricular premature contractions in adult horses at rest and during exercise are related to myocardial lesions. Physiological changes associated with the adaptive period are probably the main factors contributing to ventricular premature contraction (Yamamoto et al., 1992). Since none of the studied animals had clinical signs of cardiac problems or insufficiencies, it could be suggested that ventricular premature complexes are physiological cardiac arrhythmias.

\section{Conclusion}

In the present communication, provides the different cardiac abnormalities in healthy young local breeds of sheep and goats in Andhra Pradesh.

\section{Author's Contribution and Competing Interests}

All authors had equally contributed to complete the work based on the need. Authors declare that they have no competing interests.

\section{Acknowledgement}

Corresponding author expressed thanks to Sravani, Santhosh (Veterinary Assistants) and final year B.V.Sc \& A.H. (2009 batch) students for their active involvement in the regular ECG recordings. All the authors are thankful to Sri Venkateswara Veterinary University for providing facilities to carry out this work.

\section{References}

[1] Barbosaa RR, Fontenele-Netoa JD, Soto-Blanco B (2008) Toxicity in goats caused by oleander (Nerium oleander). Research in Veterinary Science, 85, 279-281

[2] Cebra C and Cebra M (2002) Diseases of the cardiovascular system. In Sheep and goat medicine, edited by Pugh, D.G., 1 ed., Saunders, pp: 393-396.

[3] Miller RH, Lehmkuhl LB, Bonagura JD, Beall MJ (1999) Retrospective analysis of the clinical utility of ambulatory electrocardiographic (Holter) recordings in syncopal dogs: 44 cases (19911995), Journal Veterinary Internal Medicine. 13, 111-122.

[4] Pourjafar M, Badiei K, Chalmeh AA, Sanati AR, Bagheri MH, Badkobeh M, Shahbazi A (2011) Cardiac arrhythmias in clinically healthy newborn Iranian fat tailed lambs. Global Veterinaria, 6, 185189.

[5] Radostits OM, Gay CC, Hinchcliff KW, Constable PD (2007) Diseases of the cardiovascular system. In Veterinary medicine: a Text Book of the Diseases of Cattle, Horses, Sheep, Pigs and Goats, 10 ed. Elsevier, pp: $399-438$.

[6] Rezakhani A, Papahn AA, Gheisari HR (2004) Cardiac dysrhythmias in clinically healthy heifers and cows. Revue de Médecine Vétérinaire, 155: 159-162.

[7] Rudolph AM (2001) Congenital Diseases of the Heart: Clinicalphysiological Considerations. Armonk, NY: Futura.

[8] Smith FWK and Hadlock DJ (1995) Electrocardiography. In: Manual of canine and feline cardiology, 2nd ed. (M. S. Miller, L. P. Tilley, Eds.). W. B. Saunders. Philadelphia.

[9] Smith M and Sherman DM (2009) Goat Medicine, 2nd edn, WileyBlackwell, p. 320.

[10]Sudhakara Reddy B, Somasekhar Reddy B, Solmon Raju KG, Sivajothi S (2013) Electrocardiographic Studies in Adult Sheep. The Indian Journal off Veterinary Science. Vol. 1(2) Dec'13. 43 - 47.

[11]Sudhakara Reddy B, Varaprasad Reddy LSS, Solmon Raju KG, Sivajothi S (2014) Electrocardiographic Studies in Adult Osmanabadi Goats. The Journal of Veterinary Science. Photon 115 (2014) 333 337.

[12]Wren C (2006) Cardiac arrhythmias in the fetus and newborn. Seminars in Fetal \& Neonatal Medicine, 11, 182-190.

[13] Yamamoto K, Yasuda J, Too K (1992) Arrhythmias in newborn Thoroughbred foals. Equine Veterinary Journal, 23, 169- 173. 